\title{
The role of ganciclovir for the management of cytomegalovirus retinitis in HIV patients: Pharmacological review and update on new developments
}

\author{
AliCE TSENG PharmD, MiCHELLE FOISY PharmD
}

\begin{abstract}
A TSENG, M FOISY. The role of ganciclovir for the management of cytomegalovirus retinitis in HIV patients: Phar-
\end{abstract} macological review and update on new developments. Can J Infect Dis 1996;7(3):183-194.

\begin{abstract}
OBJECTIVE: To review the pharmacology and pharmacokinetics of intravenous, oral and intraocular ganciclovir, and to discuss the role of these various formulations in the management of cytomegalovirus (CMV) retinitis in AIDS patients. DATA SOURCES: A MEDLINE search (1987 through November 1995) of English-language literature using the main medical subject headings 'ganciclovir' and 'cytomegalovirus', and the subheading 'acquired immunodeficiency syndrome'. Relevant articles were also selected from references of identified articles. Abstracts from recent medical conferences of infectious diseases, pharmacology and human immunodeficiency virus were screened for additional data. STUDY SELECTION AND DATA EXTRACTION: All articles and abstracts discussing the use of ganciclovir for the management or prophylaxis of CMV retinitis in AIDS patients were considered for inclusion. Pertinent information, as judged by the authors, was selected and synthesized for discussion.

DATA SYNTHESIS: Ganciclovir has demonstrated virustatic activity against CMV, and is often administered $5 \mathrm{mg} / \mathrm{kg}$ intravenously every $12 \mathrm{~h}$ as first-line therapy for CMV retinitis. Intravenous maintenance therapy at $5 \mathrm{mg} / \mathrm{kg}$ daily is usually effective at delaying retinitis progression for approximately 60 to 70 days. Neutropenia and thrombocytopenia are observed frequently, often necessitating interruption or discontinuation of therapy. Local drug administration may delay disease progression even further, and may be considered for patients who are intolerant to or failing intravenous therapy. However, systemic ganciclovir should be encouraged to reduce the risk of developing contralateral eye or endorgan CMV disease. Oral ganciclovir at $1 \mathrm{~g}$ tid is almost as effective as intravenous ganciclovir $5 \mathrm{mg} / \mathrm{kg} /$ day in delaying retinitis progression and is associated with fewer line-related complications. Absorption, drug interactions, cost and compliance should also be considered.

CONCLUSIONS: Until recently, ganciclovir was available only for intravenous use. Recent developments allow for intraocular and oral administration of this agent. A clear understanding of the advantages and disadvantages of these new formulations is required in order to select the most appropriate product for managing CMV retinitis in AIDS patients. (Pour le résumé, voir page 184)
\end{abstract}

Key words: AIDS, Ganciclovir, Cytomegalovirus retinitis

The Toronto Hospital, The Wellesley Hospital and Faculty of Pharmacy, University of Toronto, Toronto, Ontario Correspondence and reprints: Dr Alice Tseng, Immunodeficiency Clinic, The Toronto Hospital - General Division, College Wing, G-315,

101 College Street, Toronto, Ontario M5G 2C4. Telephone 416-340-5077, fax 416-340-4890

Received for publication December 14, 1995. Accepted March 13, 1996 


\title{
Rôle du ganciclovir dans le traitement de la rétinite à cytomégalovirus chez les patients VIH-positifs : survol pharmacologique et mise à jour
}

\begin{abstract}
OBJECTIF : Revoir la pharmacologie et la pharmacocinétique du ganciclovir par voies intraveineuse, orale et intraoculaire et discuter du rôle de ces diverses formules sur le traitement de la rétinite à cytomégalovirus (CMV) chez des sidéens.

SOURCE DES DONNÉES : Une interrogation du réseau MEDLINE (entre 1987 et novembre 1995) pour la littérature de langue anglaise à partir des termes médicaux " ganciclovir » et " cytomégalovirus » et de la sous-rubrique " syndrome d'immunodéficience acquise ». Des articles pertinents ont également été choisis à partir des sources mentionnés dans les articles identifiés. Nous avons passé en revue des résumés provenant de conférences médicales récentes et portant sur les maladies infectieuses, la pharmacologie et le virus de l'immunodéficience humaine pour y prélever des données additionnelles.

SÉLECTION DES ÉTUDES ET EXTRACTION DES DONNÉES : Tous les articles et résumés abordant l'emploi du ganciclovir pour le traitement ou la prophylaxie de la rétinite à $\mathrm{CMV}$ chez les patients sidéens ont été étudiés en vue de leur inclusion. Les renseignements pertinents selon le jugement des auteurs ont été sélectionnés et synthétisés aux fins de la discussion.

SYNTHÈSE DES DONNÉES : Le ganciclovir a démontré une activité virustatique contre le CMV et est souvent administré à raison de $5 \mathrm{mg} / \mathrm{kg}$ par voie intraveineuse à toutes les 12 heures, comme traitement de première ligne de la rétinite à CMV. Le traitement d'entretien intraveineux à raison de $5 \mathrm{mg} / \mathrm{kg}$ par jour est habituellement efficace à retarder la progression de la rétinite pendant environ 60 à 70 jours. La neutropénie et la thrombocytopénie sont souvent observées et justifient fréquemment l'interruption ou la cessation du traitement. L'administration locale du médicament peut retarder davantage la progression de la maladie et peut être envisagée chez des patients qui ne tolèrent pas le traitement intraveineux ou si ce dernier échoue. Toutefois, le ganciclovir par voie systémique doit être favorisé afin de réduire le risque d'installation d'une maladie à CMV à l'oeil controlatéral ou à un organe cible. Le ganciclovir oral à $1 \mathrm{~g}$ t.i.d. est presque toujours aussi efficace que le ganciclovir par voie intraveineuse à $5 \mathrm{mg} / \mathrm{kg}$ par jour pour retarder la progression de la rétinite et est associé à un moins grand nombre de complications. L'absorption, les interactions médicamenteuses, le coût et l'observance thérapeutique doivent également être tenus en ligne de compte.

CONCLUSIONS : Jusqu'à récemment, le ganciclovir n'était offert que pour un usage intraveineux. De récents progrès accomplis permettent désormais l'administration intraoculaire et orale de cet agent. Il faut bien comprendre les avantages et les inconvénients de ces nouvelles formules pour choisir le produit le plus approprié pour le traitement de la rétinite à CMV chez les sidéens.
\end{abstract}

$\mathrm{G}_{\mathrm{s}}^{\mathrm{a}}$ anciclovir sodium (9-[1,3-dihydroxy-2-propoxymethyl] guanine or DHPG) is a synthetic nucleoside analogue of 2 -deoxyguanosine. Ganciclovir possesses activity against members of the Herpesviridae family as well as other DNA viruses. Approved indications for its use include treatment of cytomegalovirus (CMV) retinitis in immunocompromised hosts, including those with AIDS and organ transplantation recipients (1). Other potential uses of ganciclovir are for CMV disease involving the gastrointestinal tract, the lung and the liver and for the prevention of CMV in transplant recipients and AIDS patients. This article will provide a pharmacological review of ganciclovir and focus on its role in the management of CMV retinitis in AIDS patients.

\section{PHARMACOLOGY}

Structure-activity relationships: Ganciclovir is structurally related to acyclovir and the naturally occurring purine nucleoside analogue 2'-deoxyguanosine. It differs from acyclovir by the addition of a second terminal hydroxymethyl group at the $\mathrm{C}-2$ position of the acyclic side-chain on the ribose ring. Compared with acyclovir, this addition confers increased activity against CMV and less selectivity for viral DNA (2).

Mechanism of action: For antiviral activity, ganciclovir must be converted to the triphosphate form intracellularly through a series of enzymatic reactions. Viral thymidine kinase (in herpes simplex virus [HSV] types 1 and 2 and varicella zoster virus [VZV]) or host-encoded deoxyguanosine kinase (for CMV and Epstein-Barr virus [EBV]) are responsible for catalyzing the rate-limiting reaction of ganciclovir to ganciclovir monophos- phate. Subsequent conversion of the monophosphate to the diphosphate form occurs via cellular guanylate kinase. Phosphoglycerate kinase and several cellular kinase enzymes catalyze the final reaction of the diphosphate to the triphosphate form. In the active triphosphate form, ganciclovir inhibits viral DNA polymerase and can be incorporated into the growing DNA chains as a false nucleotide. Viral replication is inhibited as a result of both the termination of DNA chain elongation and the formation of a mutant DNA chain. Although ganciclovir triphosphate displays relative specificity for viral DNA polymerases compared with host cellular DNA polymerase, uninfected host cells are also capable of producing small amounts of ganciclovir triphosphate. The accumulation of ganciclovir triphosphate in intact host cells may result in myelosuppression $(2,3)$.

Spectrum of activity: Ganciclovir displays virustatic in vitro and in vivo activity against various members of the Herpesviridae family. While ganciclovir is used primarily for CMV infections, it also exhibits activity against HSV-1, HSV-2, human herpesvirus type 6, EBV and VZV (4). The concentration of drug required to produce $50 \%$ inhibition of viral plaque formation (ID 50 ) of ganciclovir susceptible strains of CMV ranges from 0.6 to $7.0 \mu \mathrm{M}$ (mean 3.6) (5-11). In contrast, acyclovir is relatively inactive against CMV, with $\mathrm{ID}_{50}$ values of 10 to $200 \mu \mathrm{M}(2)$. For viral strains of HSV and VZV that are acyclovir-resistant due to mutations in thymidine kinase or DNA polymerase, ganciclovir may demonstrate in vitro activity $(12,13)$. Suggested breakpoints for clinical CMV isolates are as follows: fully sensitive ID50 $5 \mu \mathrm{M}$ or less; intermediate ID50 6 to $10 \mu \mathrm{M}$; and resistant 
TABLE 1

Ganciclovir dosing guidelines for renal impairment

\begin{tabular}{|c|c|c|c|}
\hline \multirow{2}{*}{$\begin{array}{l}\text { Creatinine clearance } \\
\qquad(\mathrm{mL} / \mathrm{min})^{*}\end{array}$} & \multicolumn{2}{|c|}{ Intravenous dose } & \multirow[b]{2}{*}{ Oral maintenance dose } \\
\hline & Induction & Maintenance & \\
\hline$\geq 70$ & $5 \mathrm{mg} / \mathrm{kg}$ every $12 \mathrm{~h}$ & 5 mg/kg every $24 \mathrm{~h}$ & $\begin{array}{c}1000 \mathrm{mg} \text { tid or } 500 \mathrm{mg} \text { every } 3 \mathrm{~h} \\
\text { (6 times/day) }\end{array}$ \\
\hline $50-69$ & $2.5 \mathrm{mg} / \mathrm{kg}$ every $12 \mathrm{~h}$ & $2.5 \mathrm{mg} / \mathrm{kg}$ every $24 \mathrm{~h}$ & 1500 mg daily or 500 mg tid \\
\hline $25-49$ & $2.5 \mathrm{mg} / \mathrm{kg}$ every $24 \mathrm{~h}$ & $1.25 \mathrm{mg} / \mathrm{kg}$ every $24 \mathrm{~h}$ & 1000 mg daily or 500 mg bid \\
\hline $10-24$ & $1.25 \mathrm{mg} / \mathrm{kg}$ every $24 \mathrm{~h}$ & $0.625 \mathrm{mg} / \mathrm{kg}$ every $24 \mathrm{~h}$ & 500 mg daily \\
\hline$<10$ & $\begin{array}{l}1.25 \mathrm{mg} / \mathrm{kg} 3 \text { times weekly, } \\
\text { following hemodialysis }\end{array}$ & $\begin{array}{l}0.625 \mathrm{mg} / \mathrm{kg} \text { every } 24 \mathrm{~h} 3 \text { times } \\
\text { weekly, following hemodialysis }\end{array}$ & $\begin{array}{c}500 \text { mg } 3 \text { times weekly, following } \\
\text { hemodialysis }\end{array}$ \\
\hline
\end{tabular}

${ }^{*}$ Creatinine clearance $(\mathrm{CrCl})$ can be calculated by the formula $\mathrm{CrCl}(\mathrm{mL} / \mathrm{min})=([140$-age in years] [Ideal body weight in $\mathrm{kg}]) /(50 \times[\mathrm{serum} \mathrm{creatinine}$ in $\mu \mathrm{mol}]) \times 60 . \mathrm{CrCl}$ for females $=0.85$ times this value. Adapted from reference 1

ID50 greater than $10 \mu \mathrm{M}$ or four times the pretreatment value $(14,15)$.

Synergism: In vitro synergy of foscarnet and ganciclovir against CMV has been observed (16). Clinically, the combination may result in lower doses of each agent used or it may be used to overcome reported resistance to both agents alone.

Development of resistance: Although the incidence and clinical significance of ganciclovir resistance remain to be fully elucidated, one study reported an $8 \%$ incidence of ganciclovir-resistant CMV strains in AIDS patients receiving therapy for longer than three months (17). Several mechanisms of viral resistance may exist. Since antiviral activity is dependent on ganciclovir triphosphate, resistance may develop from decreased phosphorylation of ganciclovir. Thus, a decrease in or lack of viral thymidine kinase or alterations in substrate specificity of the enzyme may occur $(2,17)$. Ganciclovir may or may not display cross-resistance with foscarnet or acyclovir (2). The possibility of viral resistance should be considered in patients who exhibit poor clinical response to therapy or in those with persistent viral shedding (17).

\section{PHARMACOKINETICS}

Previously, ganciclovir was available only for parenteral administration. New developments, however, have now allowed this agent to be administered orally as well as intraocularly.

Absorption: The oral bioavailability of ganciclovir is quite low and is estimated to be approximately $6 \%$ to $9 \%(18,19)$. The absorption of oral ganciclovir is increased when taken with food, with an average increase in the area under the curve (AUC) of $22 \%(20)$. When taken with food, both intrapatient and interpatient variability are low (19). Absorption becomes nonlinear with higher daily doses (6 g/day) and with larger doses (1500 to $2000 \mathrm{mg}$ /dose) $(18,19)$. Bioavailability is comparable for regimens of $500 \mathrm{mg}$ orally every $3 \mathrm{~h}$, six times daily, and $1 \mathrm{~g}$ orally every $8 \mathrm{~h}$ (19).

Distribution: Ganciclovir is only $1 \%$ to $2 \%$ bound to plasma proteins (2). The volume of distribution after initial and steady state dosing is $15.3 \mathrm{~L} / 1.73 \mathrm{~m}^{2}$, and 30 to $70 \mathrm{~L}$, respectively (21). Ganciclovir concentrations in the kidneys are three- to sevenfold higher than in heart blood. Concentrations observed in the liver, testes and lung are similar to heart blood concentrations (6). Cerebrospinal fluid concentrations are estimated to be $24 \%$ to $67 \%$ of serum concentrations (22). Following intravenous ganciclovir, vitreous fluid concentrations are often lower than corresponding plasma concentrations $(7,23,24)$. The volume of distribution in the vitreous is approximately $11.7 \mathrm{~mL}$ after a $200 \mu \mathrm{g}$ intravitreal injection (25).

It is unknown whether ganciclovir is distributed into human milk. However, considering its large volume of distribution, low protein binding and structural similarity to acyclovir, which has been shown to penetrate human milk, ganciclovir may penetrate milk (2). Since the potential for serious adverse effects in the nursing infant exists, the manufacturer recommends that ganciclovir should not be given to breast-feeding mothers. Nursing may be resumed $72 \mathrm{~h}$ after the last dose (1).

Elimination: Up to $100 \%$ of ganciclovir is eliminated unchanged in the urine; thus, patients with renal dysfunction require a dose reduction (26) (Table 1). In patients with normal renal function, the mean elimination half-life after multiple doses is 2.5 to $4.2 \mathrm{~h}(6,22,26,27)$. A half-life of 9.5 to $29 \mathrm{~h}$ has been reported in patients with renal insufficiency (26). Following a $200 \mu \mathrm{g}$ intravitreal injection, half-life in the vitreous was estimated to be $13.3 \mathrm{~h}$ (25).

Approximately $53 \%$ of ganciclovir is removed from plasma after $4 \mathrm{~h}$ of hemodialysis (27) and almost $90 \%$ of ganciclovir is removed by continuous venovenous hemodialysis (28).

Drug concentrations: Table 2 summarizes serum concentrations obtained after intravenous, oral and intravitreal administration of ganciclovir.

Plasma drug concentrations: In a prospective study of 28 AIDS patients receiving intravenous ganciclovir for CMV retinitis, mean plasma ganciclovir concentrations were $4.00 \mu \mathrm{M}$ for those receiving induction therapy ( $5 \mathrm{mg} / \mathrm{kg}$ bid) and $1.69 \mu \mathrm{M}$ for those receiving maintenance therapy ( $5 \mathrm{mg} / \mathrm{kg} /$ day) (23).

Oral regimens of $500 \mathrm{mg}$ every $3 \mathrm{~h}$, six times daily and $1 \mathrm{~g}$ every $8 \mathrm{~h}$ yielded mean peak concentrations of 3.92 to $4.70 \mu \mathrm{M}$, mean trough concentrations of 0.78 to $1.18 \mu \mathrm{M}$ and mean $\left.\operatorname{AUCs}_{(0-24} \mathrm{h}\right)$ of 60.3 to $62.3 \mu \mathrm{M} \cdot \mathrm{h}$ (19). In the same study, administration of a single dose of intravenous ganciclovir $(5 \mathrm{mg} / \mathrm{kg}$ ) resulted in a mean peak of $32.4 \mu \mathrm{M}$, mean trough (computed as the mean of the 0-hour and 24-hour concentrations) of less than $0.2 \mu \mathrm{M}$ (ie, below the quantification limit of the assay) and mean total AUC of $86.6 \mu \mathrm{M} \cdot \mathrm{h}(19)$. 
TABLE 2

Ganciclovir concentrations

\begin{tabular}{|c|c|c|c|c|c|c|c|}
\hline \multirow{2}{*}{$\begin{array}{c}\text { Dose and route of } \\
\text { administration }\end{array}$} & \multirow[b]{2}{*}{ Mean $(\mu \mathbf{M})$} & \multicolumn{2}{|c|}{ Plasma } & \multicolumn{4}{|c|}{ Intravitreal } \\
\hline & & Peak $(\mu \mathrm{M})$ & Trough $(\mu \mathbf{M})$ & AUC $(\mu \mathbf{M} \cdot \mathbf{h})$ & Mean $(\mu \mathbf{M})$ & Peak $(\mu \mathbf{M})$ & Reference \\
\hline $5 \mathrm{mg} / \mathrm{kg}$ iv $\mathrm{x} 1$ & - & 32.4 & $<0.2$ & 86.6 & - & - & 19 \\
\hline $5 \mathrm{mg} / \mathrm{kg}$ iv bid & $4.00 \pm 2.09$ & - & - & - & $4.74 \pm 1.49$ & - & 23 \\
\hline $5 \mathrm{mg} / \mathrm{kg}$ iv daily & $1.69 \pm 1.69$ & - & - & - & $3.29 \pm 1.84$ & - & 23 \\
\hline $\begin{array}{c}5 \mathrm{mg} / \mathrm{kg} \text { iv } 1-2 \text { times } \\
\text { daily }\end{array}$ & - & - & - & - & $3.76 \pm 1.53$ & - & 24 \\
\hline $\begin{array}{c}1 \mathrm{~g} \text { orally tid or } 500 \mathrm{mg} \\
\text { orally } 6 \mathrm{x} / \text { day }\end{array}$ & - & $3.92-4.70$ & $0.78-1.18$ & $60.3-62.3$ & - & - & 23 \\
\hline $\begin{array}{c}200 \mu \mathrm{g} \text { inj every } 3 \text { days } \\
\text { x } 15 \text { days }\end{array}$ & $<0.40$ & - & - & - & - & 63.86 & 25 \\
\hline $1 \mu \mathrm{g} / \mathrm{h}$ implant & - & - & - & - & 16.06 & - & 29 \\
\hline
\end{tabular}

AUC Area under the curve; inj Intravitreal injection; iv Intravenous

Systemic absorption of ganciclovir after intravitreal injection is minimal (25).

Intravitreal drug concentrations: In the treatment of CMV retinitis, achieving inhibitory concentrations of ganciclovir in the vitreous fluid of the eye may play an important role in the successful suppression of retinal viral replication. The relationship between plasma and intravitreal drug concentrations has not been fully elucidated. Following intravenous drug administration, intravitreal concentrations are assumed to be related to plasma AUC. With direct administration of drug into the eye, achievable local concentrations may be much higher, due to the vitreous fluid's small volume of distribution and to longer elimination.

After intravenous administration: Kupperman et al (24) measured ganciclovir levels in vitreous samples obtained intraoperatively from 23 eyes of 22 AIDS patients with retinal detachments associated with CMV retinitis. The mean extent of retinitis at the time of surgery was $44 \pm 21 \%$. Seventeen patients had been on maintenance ganciclovir, and five patients had been receiving induction therapy for longer than two weeks before surgery. The overall mean intravitreal ganciclovir concentration for all samples was $3.76 \pm 1.53 \mu \mathrm{M}$. There was no correlation between the intravitreal ganciclovir level and the extent of either retinitis or retinal detachment. There was also no statistically significant difference in mean intravitreal concentrations between patients receiving induction versus maintenance therapy, although this may be a reflection of the small sample size. The authors concluded that mean intravitreal ganciclovir concentrations obtained with intravenous administration were below the $\mathrm{ID}_{50}$ of many clinical CMV isolates and may be associated with disease progression while the patient is on maintenance therapy (24).

More recently, Arevalo et al (23) prospectively studied 28 AIDS patients with CMV retinitis and retinal detachment. Undiluted vitreous and plasma samples were taken at the time of retinal reattachment surgery. Twenty-four vitreous samples were obtained from patients receiving intravenous ganciclovir $10 \mathrm{mg} / \mathrm{kg} /$ day and 30 from patients receiving intravenous ganciclovir $5 \mathrm{mg} / \mathrm{kg} /$ day. Analyses were done to correlate drug concentration with time of administration of last dose. In pa- tients receiving induction therapy, the mean intravitreous ganciclovir concentration was $4.74 \pm 1.49 \mu \mathrm{M}$, versus $3.29 \pm 1.84 \mu \mathrm{M}$ in patients receiving maintenance therapy $(\mathrm{P}=0.005)$. Again, there was no significant correlation between vitreous drug concentration and the extent of either retinitis or retinal detachment (23).

After oral administration: No data are available regarding intravitreal drug concentrations following oral ganciclovir administration. Since AUCs achieved with oral regimens are approximately $70 \%$ of those achieved with intravenous ganciclovir (19), one may presume that intravitreal levels will be proportionally lower.

After intravitreal administration: In a patient who received $200 \mu \mathrm{g}$ injections every three days for 15 days, the concentration of ganciclovir in the intravitreal fluid immediately postinjection was $63.86 \mu \mathrm{M}$, while plasma ganciclovir concentrations remained less than $0.4 \mu \mathrm{M}(25)$. At 51.4 and $97.3 \mathrm{~h}$, intravitreal ganciclovir concentrations were 4.6 and $0.41 \mu \mathrm{M}$, respectively. The half-life in vitreous fluid was estimated to be $13.3 \mathrm{~h}$ (versus serum half-life of 2 to $4 \mathrm{~h}$ ), suggesting that intravitreal injections should be given twice weekly to ensure that ganciclovir concentrations remain above the mean ID $_{50}$ of CMV for approximately $62 \mathrm{~h}(25)$.

Martin et al (29) performed a randomized controlled clinical trial to assess the safety and efficacy of $1 \mu \mathrm{g} / \mathrm{h}$ of ganciclovir intraocular implants for the treatment of newly diagnosed CMV retinitis in 26 AIDS patients. Intraocular drug levels were measured from vitreous samples obtained at the time of implant exchange or retinal detachment surgery. The mean vitreous drug level in eight eyes was $16.06 \mu \mathrm{M}$ (29).

\section{DRUG INTERACTIONS}

Table 3 summarizes common drug interactions with ganciclovir, and provides recommendations for management and monitoring.

Zidovudine: Concomitant administration of zidovudine $(600$ to $1200 \mathrm{mg}$ daily) and ganciclovir ( $5 \mathrm{mg} / \mathrm{kg}$ once or twice daily) resulted in hematological toxicity in $82 \%$ of AIDS patients, with neutropenia being the most common side effect (55\%) (30). In a controlled pharmacokinetic study, administration of zidovu- 
TABLE 3

Ganciclovir drug interactions

\begin{tabular}{|c|c|c|c|}
\hline $\begin{array}{l}\text { Drug combination with } \\
\text { ganciclovir }\end{array}$ & $\begin{array}{l}\text { Common side } \\
\text { effects/toxicity }\end{array}$ & Comments & Monitoring \\
\hline AZT & $\begin{array}{l}\text { 个risk of neutropenia, ane- } \\
\text { mia }\end{array}$ & $\begin{array}{l}\text { Hold AZT during induction therapy with } \\
\text { ganciclovir. Reinstitute with caution dur- } \\
\text { ing maintenance or switch to } \mathrm{ddl} / \mathrm{ddC}\end{array}$ & $\begin{array}{l}\text { CBC with differential } 3 \text { times } \\
\text { weekly initially, } \\
\text { then weekly }\end{array}$ \\
\hline $\begin{array}{l}\text { Amphotericin B, dapsone, } \\
\text { flucytosine, pentamidine } \\
\text { iv, primaquine, pyrimeth- } \\
\text { amine, TMP/SMX, tri- } \\
\text { metrexate }\end{array}$ & $\begin{array}{l}\text { 个risk of bone marrow toxic- } \\
\text { ity }\end{array}$ & Cautious use of combinations is warranted & CBC for blood dyscrasias \\
\hline ddl & $\begin{array}{l}\text { With oral ganciclovir: } \uparrow d d \text { l } \\
\text { concentration }>100 \% \text {; } \\
\downarrow \text { ganciclovir concentra- } \\
\text { tion } \\
20 \% \text { (with sequential } \\
\text { administration) } \\
\text { With iv ganciclovir: } \uparrow d d l \\
\text { concentration }>70 \%\end{array}$ & $\begin{array}{l}\text { Potential for } \uparrow d d \text { l toxicity and } \\
\downarrow \text { ganciclovir efficacy. Administer oral } \\
\text { ganciclovir before/with ddl to minimize } \\
\text { effect on ganciclovir absorption }\end{array}$ & $\begin{array}{l}\text { ddl toxicity and progression } \\
\text { of CMV disease }\end{array}$ \\
\hline Imipenem & 个risk of seizures & $\begin{array}{l}\text { Do not exceed } 2 \mathrm{~g} / \text { day of imipenem. } \\
\text { Dose adjust both agents in renal failure }\end{array}$ & SCr, urea \\
\hline Probenecid & $\begin{array}{l}\downarrow \text { ganciclovir clearance, } \\
\text { leading to } \uparrow \text { ganciclovir } \\
\text { AUC of } 50 \%\end{array}$ & $\begin{array}{l}\text { Avoid concomitant use due to potential } \\
\text { for } \uparrow \text { risk of dose-related ganciclovir } \\
\text { toxicities, risk of probenecid side effects } \\
\text { (eg, headache, gastrointestinal upset, } \\
\text { rash) and interference with renal } \\
\text { elimination of other drugs a patient may } \\
\text { be taking concomitantly }\end{array}$ & \\
\hline
\end{tabular}

AUC Area under the curve; AZT Zidovudine; CBC Complete blood count; CMV Cytomeglovirus; ddC Dideoxycytidine; ddI Didanosine; iv Intravenous; SCr Serum creatinine; TMP/SMX Trimethoprim/sulfamethoxazole

dine $100 \mathrm{mg}$ orally every $4 \mathrm{~h}$, five times daily, with oral ganciclovir $1 \mathrm{~g}$ every $8 \mathrm{~h}$ resulted in a $14.5 \%$ increase in zidovudine AUC $(\mathrm{P}=0.032)$ (31). Changes in hematological parameters were not assessed in this study. In an open-label clinical trial, 113 patients (80 with AIDS, 33 with AIDS-related complex) were treated with zidovudine $200 \mathrm{mg}$ orally every $4 \mathrm{~h}$ for a median duration of 152 days (range five to 386) (32). Multiple regression analysis indicated that concurrent ganciclovir was associated with an increased risk of anemia and thrombocytopenia.

Due to the potential for additive hematotoxicity, it is recommended that these agents not be given concomitantly during the induction phase of ganciclovir (1).

Didanosine: A significant two-way interaction has been demonstrated between didanosine (ddI) and oral ganciclovir. In a multiple dose crossover pharmacokinetic interaction study, 13 human immunodeficiency virus (HIV) -positive patients received ganciclovir $1 \mathrm{~g}$ orally every $8 \mathrm{~h}$ and ddI $200 \mathrm{mg}$ orally every $12 \mathrm{~h}$ (31). Ganciclovir and ddI were administered both sequentially (ie, ddI $2 \mathrm{~h}$ before oral ganciclovir) and simultaneously to evaluate the effect of the ddI buffer on the absorption of ganciclovir. In the presence of ganciclovir, significant increases in ddI AUC were noted with both sequential and simultaneous administration (114.6\% and $107.7 \%$, respectively, $\mathrm{P}<0.001)$. In addition, the AUC of ganciclovir was decreased by $21.4 \%(\mathrm{P}=0.002)$ when administered $2 \mathrm{~h}$ after ddI; no sig- nificant changes in renal clearance of either drug were observed (31).

In a randomized, three-way crossover trial, 13 asymptomatic HIV-positive males received the following regimens in random order: intravenous ganciclovir $5 \mathrm{mg} / \mathrm{kg}$ every $12 \mathrm{~h}$ for three days; ddI $200 \mathrm{mg}$ orally every $12 \mathrm{~h}$ for three days; and the two agents in combination for three days (33). In the presence of ganciclovir, both the mean AUC and peak serum concentration of ddI increased significantly $(70.4 \%, \mathrm{P}<0.001$, and $49.3 \%, \mathrm{P}=0.024$, respectively). No significant changes in time to maximum serum concentrations, half-life or renal clearance of ddI were observed. In the presence of ddI, a modest increase in ganciclovir AUC (6.2\%, P=0.018) was noted (33).

The mechanism for this interaction is unknown. Patients receiving both ddI and ganciclovir should be closely monitored for development of ddI-related toxicities $(31,33)$.

Probenecid: Probenecid decreases the renal clearance of ganciclovir by competition for renal tubular secretion, resulting in an increase of ganciclovir AUC by approximately 50\% (31). Administration of this combination is not recommended, for several reasons, including the potential for an increased risk of dose-related ganciclovir toxicities, the risk of side effects secondary to probenecid (eg, headache, gastrointestinal upset, rash) and the potential interference with renal elimination of drugs concomitantly administered. 
Imipenem-cilastatin: Generalized seizures have been reported in six patients receiving ganciclovir and imipenemcilastatin together. The risks versus benefits should be considered before administration of the combination (2).

Cyclosporine: Nephrotoxicity may be increased when cyclosporine and ganciclovir are administered concomitantly (34). Others: Agents that interfere with replication of rapidly dividing cell populations, such as bone marrow, spermatogonia and germinal layers of skin and gastrointestinal mucosa, may have additive toxicity when given in conjunction with ganciclovir and should be used with caution. Such agents include dapsone, parenteral pentamidine, amphotericin $\mathrm{B}$, trimethoprimsulfamethoxazole (TMP/SMX), flucytosine, vincristine, vinblastine and adriamycin (1). In vitro cytotoxicity assays with human embryonic lung (MRC-5) cells suggest that ganciclovir, dapsone, amphotericin B and TMP/SMX are all associated with reductions in cellular metabolism of $17 \%$ to $40 \%$ (35). While no synergy or antagonism was noted with these combinations, there is presumably still the risk of additive cytotoxicity with concurrent administration of these drugs.

\section{CLINICAL TRIALS}

Management of CMV retinitis - Intravenous: Ninety per cent of AIDS patients will experience progressive disease if CMV retinitis is left untreated, while $80 \%$ of cases respond initially to ganciclovir therapy (36). Since recrudescence of CMV can occur within a few weeks of completing induction therapy, lifelong maintenance therapy with either ganciclovir or foscarnet is recommended (37).

Results from numerous open-label clinical trials suggest that ophthalmological response rates of CMV retinitis to ganciclovir vary from $81 \%$ to $100 \%(2,38-41)$. To evaluate the clinical response to ganciclovir more accurately, a system was developed to assess CMV retinopathy outcome using serial retinal photographs and three factors: development of new retinal lesions, enlargement of preexisting lesions and a change in opacification of lesion borders (42). This system was used to assess disease outcome in a controlled retrospective comparison of ganciclovir-treated versus untreated historical controls. Treatment with ganciclovir was associated with a reduction in disease progression in treated compared with untreated patients. Ganciclovir treatment was also associated with greater preservation of visual acuity (42). Data from these studies led to the licensure of ganciclovir for the treatment of CMV retinitis in AIDS patients in 1989.

In a randomized, comparative, multicentre study in AIDS patients with CMV retinitis, ganciclovir $(5 \mathrm{mg} / \mathrm{kg}$ every $12 \mathrm{~h}$ for two weeks followed by $5 \mathrm{mg} / \mathrm{kg}$ daily adjusted for renal function) was compared with foscarnet therapy $(60 \mathrm{mg} / \mathrm{kg}$ every $8 \mathrm{~h}$ for 14 days followed by $90 \mathrm{mg} / \mathrm{kg} /$ day adjusted for renal function) (43). Though the two treatment groups were equally efficacious in preventing the progression of retinitis, the overall survival was lower in the ganciclovir group (8.5 months) than in the foscarnet group (12.4 months). The survival advantage observed with foscarnet may be due to a combination of its anti-HIV activity and more antiretroviral use in the foscarnet group. Of note, in patients with renal impairment (estimated creatinine clearance less than $1.2 \mathrm{~mL} / \mathrm{min} / \mathrm{kg}$ ) ganciclovir was associated with improved survival relative to foscarnet (43). In light of these findings, foscarnet may be the initial therapy of choice in those with normal renal function. However, since foscarnet has a higher incidence of nausea, vomiting and general malaise than ganciclovir and is less convenient to administer, ganciclovir is often the preferred agent. Intravitreal: Experience with intravitreal ganciclovir suggests that this route of administration may be effective in controlling disease progression in patients who are failing or are intolerant to systemic antiviral therapy.

The use of intravitreal ganciclovir injections was first described by Henry et al (25) in an AIDS patient with rapidly progressing bilateral CMV retinitis and marked bone marrow suppression. The patient received intravitreal injections of $200 \mu \mathrm{g}$ every three days over a 15-day period followed by $200 \mu \mathrm{g}$ weekly injections over a three-month period, for a total of 28 injections. Retinitis in both eyes responded to treatment; when the patient later died as a result of severe coagulopathy, postmortem vitreal cultures were negative for CMV (25).

Successful short term results were also observed in 11 AIDS patients (14 eyes) with progressing CMV retinitis despite prior intravenous ganciclovir therapy (44). All patients received one to seven intravitreal ganciclovir injections of 200 $\mu \mathrm{g}$ for up to two months. Improvement or stabilization of visual acuity was seen in 12 (86\%) eyes. One case of retinal detachment occurred during this time (44).

Data on long term use (ie, eight to 14 months) of intravitreal ganciclovir in small numbers of patients suggest that this route of administration may be effective as maintenance therapy in patients unable to tolerate systemic therapy $(45,46)$. However, little is known about the complications associated with repeated intravitreal injections. In addition, the lack of systemic therapy may place patients at risk of developing contralateral retinitis or extraocular CMV disease $(29,47)$. Intraocular implants: A sustained-release intraocular ganciclovir implant may be considered in patients who respond to intravitreal ganciclovir injections. The surgically implanted device releases a constant amount of ganciclovir into the eye over six to eight months, thus obviating the need for frequent intraocular injections. Although implants are convenient, they are also expensive (approximately $\$ 5,000$ per implant). Early anecdotal experience in patients with progressing retinitis, despite intravenous ganciclovir therapy, suggested that intraocular implants were effective in resolving acute retinal inflammation and suppressing progression of retinitis for a mean of 70 to 123 days $(48,49)$.

Martin et al (29) conducted a randomized, controlled trial to assess the safety and efficacy of immediate versus deferred therapy with a $1 \mu \mathrm{g} / \mathrm{h}$ ganciclovir implant for the management of newly diagnosed CMV retinitis. Twenty-six patients (30 eyes) with peripheral retinal lesions, no systemic CMV disease and no prior exposure to ganciclovir or foscarnet were enrolled. Patients with unilateral retinitis were randomized to receive either immediate therapy (ie, surgical insertion of the implant within $48 \mathrm{~h}$ ) or deferred therapy (implant offered when progression occurred). If retinitis developed in the con- 
tralateral eye, that eye was also randomized to immediate or deferred therapy with an implant. Patients with bilateral retinitis served as their own controls (ie, one eye received immediate therapy and the other received deferred therapy). The primary study end-point was progression of retinitis, defined as a border advancement of greater than $750 \mu \mathrm{m}$, or the appearance of a new lesion at least $750 \mu \mathrm{m}$ in diameter. Secondary end-points included the development of contralateral retinitis, visceral CMV disease and death. Patients were monitored every two weeks by masked fundus photography, and implants were exchanged every 32 weeks. Patients who developed immediately sight-threatening retinitis or visceral CMV disease were given systemic antiviral therapy. Fourteen eyes received immediate therapy with the implant, while 16 eyes were randomized to receive deferred therapy. The median time to progression of retinitis was 15 days (range 14 to 39 days) in the deferred group, compared with an estimated 226 days in the immediate therapy group $(\mathrm{P}<0.00001)$ (29). In total, 39 eyes received an implant: 14 in the immediate therapy group, 14 in the deferred group who experienced progression, and 11 that developed contralateral retinitis during the follow-up period. The range of follow-up after treatment with the implant was 13 to 423 days. Final visual acuity was 20/25 or better in 34 of 39 eyes. Progression occurred in nine eyes. A number of these cases responded to either insertion of a new implant or to intravenous therapy for visceral disease (29). The risk of developing contralateral retinitis was $50 \%$ by 203 days of therapy; thus, in total 14 of 21 patients (67\%) developed disease in the fellow eye. Biopsy proven visceral CMV disease (most often in the gastrointestinal tract or the lungs) developed in eight of $26(31 \%)$ patients, at an estimated median of 248 days. All eight patients responded to intravenous ganciclovir. The median survival time was 295 days. Retinal detachment occurred in seven eyes (18\%). All cases were associated with posterior vitreous detachment, possibly induced by surgery. The investigators concluded that, although the implant was efficacious in treating CMV retinitis, patients were at risk of developing retinitis in the fellow eye or extraocular disease (29).

Another randomized, controlled, multicentre trial was conducted by the Chiron Ganciclovir Implant Study Group (47) to evaluate the safety and efficacy of a sustained-release ganciclovir implant compared with standard intravenous ganciclovir therapy for the treatment of $\mathrm{CMV}$ retinitis. One hundred and eighty-eight patients with newly diagnosed CMV retinitis and no extraocular CMV disease were enrolled in the study; of these, 173 were eligible to receive treatment and were randomized to either a $1 \mu \mathrm{g} / \mathrm{h}(\mathrm{n}=62)$ or $2 \mu \mathrm{g} / \mathrm{h}$ implant $(\mathrm{n}=55)$ or intravenous ganciclovir $(n=56)$. The primary study end-point was progression of retinitis, which was defined as movement of retinitis borders of $\pm 750 \mu \mathrm{m}$, or development of a new retinal lesion. Progression was determined by a central masked fundus photograph reading centre. Secondary end-points included development of retinitis in the fellow eye, development of extraocular CMV disease, quality of life, and death. Patients in the intravenous ganciclovir group who progressed were offered an implant.

The median duration of follow-up was 164 days in the
$1 \mu \mathrm{g} / \mathrm{h}$ implant group, 153 days in the $2 \mu \mathrm{g} / \mathrm{h}$ implant group and 81 days in the intravenous group. Median time to progression was 216 days for the combined implant group versus 104 days for the intravenous ganciclovir group $(\mathrm{P}<0.0001)$. Patients receiving implants experienced a slight decrease in visual acuity in the immediate postoperative period; visual acuity returned to preoperative levels within two to four weeks. Other complications in the implant recipients included three cases $(1.2 \%)$ of endopthalmitis, which led to loss of vision in two patients, as well as a significantly higher incidence of retinal detachments compared with the intravenous group (12\% versus $5 \%$, respectively). Retinal detachment occurred earlier (ie, within the first three months postsurgery) in the implant group, but the risk of retinal detachment increased with time (presumably as a reflection of disease progression) in the intravenous arm (47). The incidence of fellow eye involvement was $40 \%$ in the combined implant group at a median time of 87 days, compared with $16 \%$ in the intravenous group at a median time of 119 days (not statistically significant). Extraocular disease was significantly more frequent in the implant recipients $(15.3 \%)$. There was no statistically significant difference in survival between the combined implant and intravenous groups (140 days and 150 days, respectively) (47).

Oral: The efficacy of oral $(3 \mathrm{~g} /$ day $)$ versus intravenous ( 5 $\mathrm{mg} / \mathrm{kg} /$ day) ganciclovir for maintenance therapy of CMV retinitis has been evaluated in three randomized, open-label, parallel group, multicentre studies (50-52). In all studies, the primary efficacy end-point was time to progression, defined as border advancement of $\pm 750 \mu \mathrm{m}$ or the appearance of a new retinal lesion. Patients were assessed by both masked retinal photographs read at a central reading centre and unmasked funduscopy by an experienced ophthalmologist (50-52).

Combined efficacy results showed a slightly shorter time to progression with the oral ganciclovir compared with intravenous ganciclovir. When progression was determined using masked retinal photographs, the mean times to progression were 62 to 66 days in the intravenous group versus 51 to 57 days in the oral group, for a difference of five to 12 days $(95 \%$ CI) in favour of the intravenous group. With funduscopic assessment, the difference in mean time to progression was statistically significant: 100 days versus 76 days for the intravenous and oral groups, respectively (50-52). According to this method of assessment, the times to development of progression were longer and the differences between the treatment groups were larger, which may reflect investigator bias as well as decreased ability to detect progression compared with the use of serial photographs. There was no statistically significant difference between the treatment arms in terms of progression to bilateral retinitis or progression of disease into zone 1, development of new lesions in infected eyes, reduction in visual acuity or functional vision, time to treatment failure or survival (50-52).

The incidence of side effects was similar between the treatment groups except for the occurrence of sepsis (17\% versus $6 \%$ ), intravenous catheter-related events ( $22 \%$ versus $6 \%$ ), neutropenia ( $25 \%$ versus $18 \%$ ) and anemia ( $21 \%$ versus $12 \%$ ) in the intravenous and oral groups, respectively. Overall, there was 
no statistically significant difference between the groups in terms of safety related premature withdrawals from therapy (50-52).

Prophylaxis of CMV end-organ disease: Spector et al (53) conducted a randomized, double-blind, placebo controlled study to evaluate the safety and efficacy of oral ganciclovir for prevention of CMV end-organ disease. Following a baseline ophthalmological examination, 725 HIV-positive, CMVseropositive patients with low CD4 counts (either less than 50 cells/mL, or less than 100 cells/mL and a prior opportunistic infection) were randomized to receive either $1 \mathrm{~g}$ ganciclovir every $8 \mathrm{~h}$ or placebo orally. Patients were assessed every two months by dilated indirect ophthalmoscopy. The mean duration of therapy was six months. Preliminary intent-to-treat analysis showed a statistically significant reduction in CMV disease in patients receiving ganciclovir compared with those on placebo ( $16 \%$ and $30 \%$, respectively, $\mathrm{P}=0.0001$ ), which led to early termination of the study. Retinitis was the most common disease manifestation and occurred in $11 \%$ of ganciclovir recipients, compared with $20 \%$ of those on placebo $(\mathrm{P}=0.001)$. A significant difference in the time to development of CMV disease was noted with oral ganciclovir ( $R R 2.2, P=0.001)$. There was no difference in survival between the two groups. Neutropenia developed in a significantly higher proportion of oral ganciclovir patients than in those on the placebo (13\% versus 6\%) (53).

As part of the study protocol, urine cultures, and occasionally blood and/or semen cultures, were performed every two months while patients were receiving treatment. The incidence of positive cultures at baseline was similar for both groups ( $42 \%$ and $44 \%$ for ganciclovir and placebo patients, respectively). After two months, the number of positive cultures in the ganciclovir group was reduced by $50 \%$, while the incidence remained constant in the placebo group. At 18 months, the average prevalence of positive CMV cultures during oral ganciclovir prophylaxis was $11 \%$, compared with $46 \%$ for the placebo group. The last isolate recovered from each patient receiving at least 90 days of treatment was tested for ganciclovir susceptibility. To date, 39 isolates from patients receiving ganciclovir for a mean 251 days (range 112 to 564) have been tested (54). Of these, 36 isolates were fully sensitive, one was moderately sensitive and two were resistant. All isolates obtained from 10 patients receiving placebo for a mean of 313 days (range 112 to 519 ) were sensitive to ganciclovir. The two resistant $\mathrm{CMV}$ isolates $\left(\mathrm{ID}_{50} 35.8\right.$ and $14.0 \mu \mathrm{M}$ ) were obtained from urine cultures after nine and 10 months of ganciclovir. After an additional four months of prophylaxis, both patients developed CMV retinitis, which was unresponsive to intravenous ganciclovir therapy. These preliminary data suggest a low overall prevalence of resistance following a mean 8.3 months of ganciclovir prophylaxis, and in two patients, resistant virus was later associated with treatment failure (54).

Another placebo controlled trial of oral ganciclovir was conducted by the Terry Beirn Community Programs for Clinical Research on AIDS (55). Between April 1993 and June 1994, 994 patients with a CD4 count of less than 100 cells $/ \mathrm{mm}^{3}$ and a positive CMV serology or culture were enrolled and randomized to receive either oral ganciclovir $1 \mathrm{~g}$ tid $(n=662)$ or a pla- cebo $(n=332)$. Unlike the previous prophylaxis study, baseline ophthalmological examinations were not performed, and subsequent examinations were conducted when patients experienced visual complaints, rather than at routine intervals. Following the interim results of the prophylaxis study by Spector et al (53) in September 1994, patients in the placebo group were allowed to switch to open-label oral ganciclovir. The mean duration of exposure to oral ganciclovir was 9.3 months for patients initially randomized to oral ganciclovir and 2.1 months for patients randomized to placebo. Based on intent-to-treat analysis with follow-up data to June 1995, the investigators did not find any significant differences between the two groups with respect to development of any confirmed CMV disease, CMV retinitis, CMV gastrointestinal disease or death. Furthermore, patients who received oral ganciclovir experienced significantly more adverse effects, including neutropenia, compared with those on placebo (25\% versus $16 \%$, $\mathrm{P}=0.001$ ) (55).

In contrast to Spector et al (53), the investigators of this study concluded that their results did not support the use of oral ganciclovir for prophylaxis of CMV disease (55). However, other factors should be considered when interpreting these results. Absence of a baseline assessment may have resulted in inadvertent inclusion of patients with mild or peripheral CMV retinitis into the study, and the lack of regular ophthalmological examinations may have resulted in an underestimation of disease development. In addition, the crossover of patients from the placebo to the oral ganciclovir group may have made it more difficult to demonstrate confirmatory results between the treatment arms.

\section{PLACE IN THERAPY OF CMV RETINITIS}

Besides ganciclovir, foscarnet is the only other readily available agent in Canada for the management of CMV retinitis. Due to its better tolerability, shorter infusion time and increased convenience, ganciclovir is often preferred as a first-line agent. Until recently, ganciclovir was available only via intravenous administration for both treatment and maintenance therapy of CMV retinitis. The development of novel formulations of ganciclovir has increased the options available to patients. However, a clear understanding of the advantages and disadvantages of these new formulations is required in order to select the most appropriate therapy for patients.

Following induction therapy with intravenous ganciclovir, patients must deal with daily intravenous infusions on an indefinite basis. However, the majority of patients eventually have progression of retinitis while on maintenance treatment (43). Intravenous ganciclovir is usually effective at delaying CMV retinitis progression for approximately 60 to 70 days (43). Often, progression of retinitis may occur because of subtherapeutic intraocular drug levels. Therefore, reinstituting therapy at induction doses can be effective in halting disease progression; patients who respond may then require continued therapy with higher doses. One must be cognizant that these patients may be at higher risk of experiencing dose-related toxicities. 
Intravitreal ganciclovir may be an alternative to intravenous ganciclovir in neutropenic and/or thrombocytopenic patients who are intolerant to foscarnet, or it may be used in combination with systemic therapy to achieve greater control of CMV retinitis (56). For patients who do not wish to receive frequent intravitreal injections, surgical insertion of an intraocular implant may be a more desirable, but more expensive option. Although the implant alone has also been shown to be more effective than intravenous ganciclovir in delaying progression of CMV retinitis (over 200 days [29,47] versus 60 to 70 days [43]), systemic antiviral therapy is also warranted to prevent the development of extraocular disease $(23,25)$. Furthermore, the immediate and chronic complications associated with local antiviral therapy need to be considered.

Oral ganciclovir is an option for maintenance therapy if a patient is experiencing frequent complications associated with a permanent central line, or if the patient wishes to avoid the inconvenience of daily intravenous infusions. However, oral ganciclovir is not recommended for patients with immediately sight-threatening retinal lesions, because it may not achieve optimal concentrations (19). The oral formulation should be used only in patients with relatively intact gastrointestinal absorption. Other issues such as potential drug interactions, cost and patient compliance should be considered. More detailed guidelines on the appropriate use of oral ganciclovir have recently been described by the Canadian CMV Advisory Board (57).

In patients who experience frequent relapses despite high dose intravenous ganciclovir or who are experiencing unmanageable toxicities, switching to foscarnet is suggested. Generally, patients should receive induction doses of foscarnet (60 $\mathrm{mg} / \mathrm{kg}$ every $8 \mathrm{~h}$ or $90 \mathrm{mg} / \mathrm{kg}$ every $12 \mathrm{~h}$ ) until stabilization of retinitis before switching to maintenance therapy (120 $\mathrm{mg} / \mathrm{kg} /$ day). As with ganciclovir, some patients may require higher doses to prevent disease progression.

In patients whose disease progresses despite trials of intravenous foscarnet and ganciclovir, a trial of the two agents in combination may be warranted (58-62). The optimal doses for combination therapy have not been clearly defined and should be tailored to individual patient response or toxicity. Initially, a trial of maintenance doses of both agents is acceptable in order to minimize toxicity. However, some patients may require induction doses of one or both agents in order to prevent disease progression. Although combination therapy may be more efficacious than either agent alone in terms of preventing retinitis progression and minimizing the rate of visual field loss (62), disadvantages include increased risk of toxicity, decreased convenience, increased cost and decreased quality of life (62).

Although preliminary data regarding the use of oral ganciclovir for CMV prophylaxis appear promising, the impact of widespread use on CMV resistance patterns is unclear. In addition, at a cost of approximately $\$ 50$ per day, the pharmacoeconomic implications need to be considered. At this time, oral ganciclovir is not approved in Canada for the prevention of CMV disease.

\section{ADVERSE EFFECTS}

Systemic administration: The manufacturer reports that ganciclovir therapy was interrupted or discontinued in $32 \%$ of patients in clinical trails due to adverse effects (1). Reinstitution of treatment resulted in ganciclovir withdrawal or interruption in some cases.

The most frequently observed side effect is hematotoxicity. Neutropenia (absolute neutrophil count [ANC] less than $1 \times 10^{9} / \mathrm{L}$ ) occurs in $38 \%$ of patients and thrombocytopenia (platelet count less than $50 \times 10^{9} / \mathrm{L}$ ) in $19 \%$ of cases. Severe neutropenia (ANC less than $0.5 \times 10^{9} / \mathrm{L}$ ) or thrombocytopenia (platelet count less than $25 \times 10^{9} / \mathrm{L}$ ) necessitates treatment interruption until the bone marrow recovers. Anemia occurs in about $2 \%$ of cases. In general, hematological toxicity is reversible and evidence of marrow recovery occurs within three to seven days (1). The incidence of neutropenia and anemia appears to be slightly lower with the oral formulation than with the intravenous drug. This is likely a reflection of the lower serum concentrations achieved with the oral drug (19).

Throughout induction therapy, white blood cell counts and platelet counts should be done daily or every two days in those with a baseline ANC less than $1 \times 10^{9} / \mathrm{L}$. During maintenance therapy complete blood counts and platelet counts should be done at least once weekly (1).

Ganciclovir-induced neutropenia may be decreased when sargramostim (GM-CSF) is co-administered $(63,64)$. Grossberg et al (63) administered GM-CSF on a compassionate use basis to patients who became neutropenic while on ganciclovir. These patients were able to tolerate ganciclovir ( 5 to $10 \mathrm{mg} / \mathrm{kg}$ daily) for up to eight months, with prevention of retinitis in the majority of patients over the treatment period.

In a phase II, multicentre, randomized, open-label study (ACTG 073) (64), 53 patients with newly diagnosed, immediately sight-threatening CMV retinitis received ganciclovir (5 $\mathrm{mg} / \mathrm{kg}$ every $12 \mathrm{~h}$ for 14 days, followed by $5 \mathrm{mg} / \mathrm{kg} /$ day maintenance) alone $(n=29)$ or in combination with GM-CSF $(n=24)$; no other potentially myelosuppressive agents were allowed during this phase. Patients randomized to the GM-CSF group received 1 to $8 \mu \mathrm{g} / \mathrm{kg}$ daily by subcutaneous injection to maintain an ANC of between 2.5 and $5 \times 10^{9} /$ L. After 16 weeks, zidovudine $600 \mathrm{mg}$ daily was added, and patients not already receiving GM-CSF were offered the agent if they became neutropenic (ANC less than $0.75 \times 10^{9} / \mathrm{L}$ ). In the first 16 weeks, patients who received ganciclovir plus GM-CSF had significantly higher neutrophil counts and delayed time to first consecutive neutropenic event compared with patients on ganciclovir alone. Patients receiving GM-CSF also missed fewer scheduled ganciclovir doses, with a trend towards a delay in recurrence of CMV retinitis. All patients who were on zidovudine plus ganciclovir eventually received GM-CSF, with sustained effects on neutrophil count. By the end of the study, there was no difference between the groups with respect to retinitis progression. There was no evidence to suggest that GM-CSF consistently induced HIV proliferation, as determined by serial HIV p24 antigen measurements. The only adverse events that occurred more frequently in the ganciclovir plus GM-CSF 
group versus ganciclovir alone were asymptomatic eosinophilia and myalgia (64).

Experience with granulocyte colony-stimulating factor (G-CSF) also appears promising. Recombinant methionyl human G-CSF (r-metHuG-CSF) was administered to seven AIDS patients with dose-limiting neutropenia (ANC less than $0.5 \times 10^{9} / \mathrm{L}$ in five patients and less than $0.58 \times 10^{9} / \mathrm{L}$ in two patients) secondary to ganciclovir (65). Three patients were also receiving concurrent myelosuppressive agents. r-metHuG-CSF was administered as $300 \mathrm{mg}$ subcutaneous injections one to three times a week, to achieve a trough ANC between 0.5 and $1.5 \times 10^{9} / \mathrm{L}$. All patients tolerated recommended doses of ganciclovir for a median of six weeks (range two to 15) while on combined therapy. No toxicity associated with r-metHuG-CSF was noted.

These data suggest that administration of a CSF may be effective in correcting ganciclovir-associated neutropenia, thus allowing for continued administration of ganciclovir, as well as other myelosuppressive agents, including zidovudine. Other factors, including cost, should be kept in mind when considering such options.

Other reported adverse reactions associated with ganciclovir include neurological toxicity in $5 \%$ of patients (dreams, ataxia, confusion, dizziness, headache, nervousness, paresthesias, psychosis, somnolence, tremor and coma), fever (2\%), rash (2\%) and abnormal liver function tests (2\%).

Local administration: The maximally tolerated intravitreal dose in humans has not yet been established. With intravitreal injections, a transient increase in intraocular pressure is frequently observed; this may result in intense ocular pain for approximately 30 mins, or even total amaurosis (by interruption of retinal vascular flow) for 1 to 10 mins after injection. Other potential complications include retinal detachment, lens damage, subconjunctival hemorrhage, keratitis, corneal ulceration, infection, optic nerve atrophy and retinal detachment (56). There may also be an increased risk of early retinal detachment associated with intraocular implants $(29,47)$.

Precautions and other considerations: In animals and in vitro mammalian cells ganciclovir caused aspermatogenesis, mutagenicity, teratogenicity (fetal growth retardation, cleft palate, an/microphthalmia, aplastic kidney and pancreas, hydrocephaly and brachygnathia in animals) and carcinogenicity. Both males and females should practise barrier contraception throughout and for 90 days after ganciclovir treatment. Ganciclovir should also be avoided during pregnancy and in nursing mothers. In addition, caution should be employed in the preparation, handling and disposal of ganciclovir. The use of latex gloves and safety glasses is recommended during its preparation (1).

\section{DOSING AND ADMINISTRATION}

An induction dose of $5 \mathrm{mg} / \mathrm{kg}$ given every $12 \mathrm{~h}$ for 14 to 21 days is recommended for the treatment of CMV retinitis. Ganciclovir should be infused intravenously over a minimum of $1 \mathrm{~h}$ (maximum concentration of $10 \mathrm{mg} / \mathrm{mL}$ ) to avoid excessive plasma concentrations, which may increase toxicity, tissue irritation and the incidence of phlebitis (1). Maintenance regi- mens include a dose of either $5 \mathrm{mg} / \mathrm{kg}$ once daily for seven days each week or $6 \mathrm{mg} / \mathrm{kg}$ once daily for five days of the week.

The dose of oral ganciclovir is $1 \mathrm{~g}$ orally tid with food for maintenance therapy of CMV retinitis. Use of this agent is not recommended in patients with sight-threatening retinitis or extraocular CMV disease, chronic diarrhea or vomiting, or in patients with potentially poor compliance (57).

For patients with renal impairment, refer to Table 1 for dosing guidelines. Ganciclovir should be given postdialysis on days when hemodialysis is performed. Dosing in dialysis should not exceed $1.25 \mathrm{mg} / \mathrm{kg} / 24 \mathrm{~h}$ (1).

Intravitreal ganciclovir in doses of 200 to $400 \mu \mathrm{g}$ in $0.1 \mathrm{~mL}$ of sterile normal saline administered every two to three days for up to 18 days followed by weekly maintenance doses have been used (56). To prepare the solution for intravitreal injection, a $500 \mathrm{mg}$ vial should be diluted with $2.5 \mathrm{~mL}$ sterile water for injection, for a concentration of $200 \mathrm{mg} / \mathrm{mL}$ ganciclovir. Next, $0.1 \mathrm{~mL}(20 \mathrm{mg})$ of this solution is diluted to $10 \mathrm{~mL}$ in preservative-free normal saline for injection, to yield a final concentration of $200 \mu \mathrm{g} / 0.1 \mathrm{~mL}$. The solution should be filtered with a $0.22 \mu \mathrm{m}$ filter before use (56). The dose should be injected by an experienced ophthalmologist 3 to $4 \mathrm{~mm}$ from the corneoscleral limbus in the inferotemporal quadrant using a tuberculin syringe and a 30 gauge needle under topical anesthesia. Surgical implantation of a $1 \mu \mathrm{g} / \mathrm{h}$ sustained-release intraocular device is generally required every four to eight months (29). Implants are available from Chiron Vision (1-800263-3557, Richmond Hill, Ontario) and cost approximately $\$ 5,000$ each.

\section{CONCLUSIONS}

Ganciclovir is an effective agent in the treatment of CMV infections. Intravenous ganciclovir should be considered as first-line induction and maintenance therapy for CMV retinitis. Dosage adjustment is necessary in renal impairment. The most serious and frequently observed side effects are neutropenia and thrombocytopenia, which may necessitate interruption or discontinuation of therapy. Routine monitoring of hematological parameters is required. Caution should be employed when using ganciclovir in combination with other myelosuppressive drugs (including zidovudine) and ddI, because of the potential for pharmacokinetic or pharmacodynamic interactions. The development of novel formulations now allows this agent to be administered intraocularly as well as orally. Although these new products may be associated with increased patient convenience, they are not without their own associated risks and complications. Therefore, careful consideration of individual patient factors is required for the selection of the most appropriate route of drug administration. The utility of oral ganciclovir for the prevention of CMV disease in HIV patients requires further study.

\section{REFERENCES}

1. Cytovene Product Monograph. Mississauga: Hoffmann-La Roche, Ltd, 1995.

2. Faulds D, Heel RC. Ganciclovir - a review of its antiviral activity, pharmacokinetic properties and therapeutic efficacy in cytomegalovirus infections. Drugs 1990;39:597-638. 
3. Collaborative DHPG Treatment Study Group: treatment of serious cytomegalovirus infections with 9-(1,3-dihydroxy-

2-propoxymethyl)guanine in patients with AIDS and other immunodeficiencies. N Engl J Med 1986;314:801-5.

4. Deeter RG, Khanderia U. Recent advances in antiviral therapy. Clin Pharm 1986;5:961-76.

5. Plotkin SA, Drew WL, Felsenstein D, et al. Sensitivities of clinical isolates of human cytomegalovirus to

9-(1,3-dihydroxy-2-propoxymethyl)guanine. J Infect Dis $1985 ; 154: 833-4$.

6. Shepp DH, Dandliker PS, de Miranda P, et al. Activity of 9-(2-hydroxy-1-(hydroxymethyl)-ethoxymethyl)guanine in the treatment of cytomegalovirus pneumonia. Ann Intern Med 1985;103:368-73.

7. Jabs DA, Wingard JR, de Bustros S, et al. BW B759U for cytomegalovirus retinitis: intraocular drug penetration. Arch Ophthalmol 1986;104:1436-7.

8. Felsenstein D, D'Amico DJ, Hirsch MS, et al. Treatment of cytomegalovirus retinitis with 9-(2-hydroxy-1(hydroxymethyl) ethoxymethyl)guanine. Ann Intern Med 1985;103:377-80.

9. Mar EC, Cheng YC, Huang ES. Effect of 9-(1,3-dihydroxy-2-propoxymethyl)guanine on human cytomegalovirus replication in vitro. Antimicrob Agents Chemother 1983;24:518-21.

10. Tyms AS, Davis JM, Jeffries DJ, et al. BW759U, an analog of acyclovir, inhibits human cytomegalovirus in vitro. Lancet 1984;ii:924-5.

11. Cole NL, Balfour HH Jr. In vitro susceptibility of cytomegalovirus isolates from immunocompromised patients to acyclovir and ganciclovir. Diagn Microbiol Infect Dis 1987;6:255-61.

12. Cheng YC, Huang ES, Lin JC, et al. Unique spectrum of activity of 9-((1,3-dihydroxy-2-propoxy)methyl)guanine against herpes viruses in vitro and its mode of action against herpes simplex virus type 1. Proc Natl Acad Sci USA 1983;80:2767-70.

13. Smee DF, Martin JC, Verhayden JPH, et al. Antiherpes activity of the acyclic nucleoside 9-(1,3-dihydroxy-2-propoxymethyl) guanine. Antimicrob Agents Chemother 1983;23:676-82.

14. Drew WL, Miner RC, Saleh E. Antiviral susceptibility testing of cytomegalovirus: criteria for detecting resistance to antivirals. Clin Diagn Virol 1993;1:179-85.

15. Drew WL. Prevalence and management of CMV resistance. Theory into practice: the role of oral ganciclovir for CMV retinitis and CMV disease. Second National Conference on Human Retroviruses and Related Infections. Washington, January 29 to February 2, 1995.

16. Manischewitz JF, Quinnan GV Jr, Lane HC, et al. Synergistic effect of ganciclovir and foscarnet on cytomegalovirus replication in vitro. Antimicrob Agents Chemother 1990;34:373-5.

17. Drew WL, Miner RC, Busch DF, et al. Prevalence of resistance in patients receiving ganciclovir for serious cytomegalovirus infections. J Infect Dis 1991;163:716-9.

18. Spector SA, Busch DF, Follansbee S, et al. Pharmacokinetic, safety and antiviral profiles of oral ganciclovir in persons infected with human immunodeficiency virus: a phase I/II study. J Infect Dis 1995;171:1431-7.

19. Anderson RD, Griffy KG, Jung D, et al. Ganciclovir absolute bioavailability and steady-state pharmacokinetics after oral administration of two $3000 \mathrm{mg} /$ day dosing regimens in human immunodeficiency virus- and cytomegalovirus-seropositive patients. Clin Ther 1995;17:425-32.

20. Byrne A, Lavelle J, Follansbee S, et al. Multiple dose crossover pharmacokinetic study to evaluate the effect of food on the relative bioavailability of oral ganciclovir. Eighth International Conference on AIDS. Amsterdam, July 19 to 24, 1992.

21. Morse GD, Shelton MJ, O'Donnell AM. Comparative pharmacokinetics of antiviral nucleoside analogues. Clin Pharmacokinet 1993;24:101-23.

22. Fletcher C, Sawchuk R, Chinnock MT, et al. Human pharmacokinetics of the antiviral drug DHPG. Clin Pharmacol Ther 1986;40:281-6.

23. Arevalo JF, Gonzalez C, Capparelli EV, et al. Intravitreous and plasma concentrations of ganciclovir and foscarnet after intravenous therapy in patients with AIDS and cytomegalovirus retinitis. J Infect Dis 1995;172:951-6.

24. Kupperman BD, Quiceno JI, Flores-Aguilar M, et al. Intravitreal ganciclovir concentration after intravenous administration for
AIDS patients with cytomegalovirus retinitis: implications for therapy. J Infect Dis 1993;168:1506-9.

25. Henry K, Cantrill H, Fletcher C, et al. Use of intravitreal ganciclovir (dihydroxy propoxymethyl guanine) for cytomegalovirus retinitis in a patient with AIDS. Am J Ophthalmol 1987;103:17-23.

26. Laskin OL, Stahl-Bayliss CM, Kalman CM, et al. Use of ganciclovir to treat serious cytomegalovirus infections in patients with AIDS. J Infect Dis 1987;155:323-7.

27. Sommadossi JP, Bevan R, Ling T, et al. Clinical pharmacokinetics of ganciclovir in patients with normal and impaired renal function. Rev Infect Dis 1988;10(Suppl 3):S507-14.

28. Boulieu R, Bastien O, Bleyzac N. Pharmacokinetics of ganciclovir in heart transplant patients undergoing continuous venovenous hemodialysis. Ther Drug Monit 1993;15:105-7.

29. Martin DF, Parks DJ, Mellow SD, et al. Treatment of cytomegalovirus retinitis with an intraocular sustained-release ganciclovir implant: a randomized controlled clinical trial. Arch Ophthalmol 1994;112:1531-9.

30. Hochster H, Dieterich D, Bozzette S, et al. Toxicity of combined ganciclovir and zidovudine for cytomegalovirus disease associated with AIDS: an AIDS clinical trials group study. Ann Intern Med 1990;113:111-7.

31. Gaines K, Wong R, Jung D. Pharmacokinetic interactions with oral ganciclovir: zidovudine, didanosine, probenecid. Tenth International Conference on AIDS. Yokohama, August 1994

32. Pinching AJ, Helbert M, Peddle B, et al. Clinical experience with zidovudine for patients with acquired immune deficiency syndrome and acquired immune deficiency syndrome-related complex. J Infect 1989;18(Suppl 1):33-40.

33. Frascino RJ, Gaines-Griffy K, Jung D, et al. Multiple dose crossover study of IV ganciclovir induction dose $(5 \mathrm{mg} / \mathrm{kg}$ IV $\mathrm{q} 12 \mathrm{~h}$ ) and didanosine (100 mg po q12h) in HIV-infected persons. 35th Interscience Conference on Antimicrobial Agents and Chemotherapy. San Francisco, September 17 to 20, 1995.

34. Lake KD. Management of drug interactions with cyclosporine. Pharmacotherapy 1991;11:110S-8S.

35. Freitas VR, Fraser-Smith EB, Matthews TR. Efficacy of ganciclovir in combination with other antimicrobial agents against cytomegalovirus in vitro and in vivo. Antiviral Res 1993;20:1-12.

36. Drew WL. Cytomegalovirus infection in patients with AIDS. Clin Infect Dis 1992;14:608-15.

37. Polis MA. Foscarnet and ganciclovir in the treatment of CMV retinitis. J Acquir Immun Defic Syndr 1992;5(Suppl 1):S3-10.

38. Masur H, Lane HC, Palestine A, et al. Effect of 9-(1,3-dihydroxy-2-propoxymethyl)guanine on serious cytomegalovirus disease in eight immunosuppressed homosexual men. Ann Intern Med 1986;104:41-4.

39. Palestine AG, Stevens G Jr, Lane HC, et al. Treatment of cytomegalovirus retinitis with dihydroxy popoxylmethyl guanine. Am J Ophthalmol 1986;101:95-101.

40. Holland GN, Sidikaro Y, Kreiger AE, et al. Treatment of cytomegalovirus retinopathy with ganciclovir. Ophthalmology 1987;94:815-23.

41. Jabs DA, Newman C, De Bustros S, et al. Treatment of cytomegalovirus retinitis with ganciclovir. Ophthalmology 1987;94:824-30.

42. Holland GN, Buhles WC, Mastre B, et al. A controlled, retrospective study of ganciclovir treatment for cytomegalovirus retinopathy. Arch Ophthalmol 1989;107:1759-66.

43. Studies of Ocular Complications of AIDS Research Group, in Collaboration with the AIDS Clinical Trials Group. Mortality in patients with the acquired immunodeficiency syndrome with either foscarnet or ganciclovir for cytomegalovirus retinitis. N Engl J Med 1992;326:213-20.

44. Ussery FM III, Gibson SR, Conklin RH, et al. Intravitreal ganciclovir in the treatment of AIDS-associated CMV retinitis. Ophthalmology 1988;95:640-8.

45. Cantrill HL, Henry K, Melroe NH, et al. Treatment of cytomegalovirus retinitis with intravitreal ganciclovir: long-term results. Ophthalmology 1989;96:367-74.

46. Heinemann M. Long-term intravitreal ganciclovir therapy for cytomegalovirus retinopathy. Arch Ophthalmol 1989;107:1767-72.

47. Chiron Ganciclovir Implant Study Group. A randomized controlled multicenter clinical trial of a sustained-release 
intraocular ganciclovir implant in AIDS patients with CMV retinitis. 35th Interscience Conference on Antimicrobial Agents and Chemotherapy. San Francisco, September 17 to 20, 1995.

48. Anand R, Font RL, Fish RH, et al. Pathology of cytomegalovirus retinitis treated with sustained release intravitreal ganciclovir. Ophthalmology 1993;100:1032-9.

49. Anand R, Nightingale S, Fish RH, et al. Control of cytomegalovirus retinitis using sustained release of intraocular ganciclovir. Arch Ophthalmol 1993;111:223-7.

50. Drew WL, Ives D, Lalezari JP, et al. Oral ganciclovir as maintenance treatment for cytomegalovirus retinitis in patients with AIDS. N Engl J Med 1995;333:615-20.

51. Squires KE, Stempien MJ, Shadman A, et al. Oral ganciclovir versus intravenous ganciclovir maintenance therapy for cytomegalovirus (CMV) retinitis in patients with AIDS: preliminary results of a phase III study. The First National Conference on Human Retroviruses and Related Infections. Washington, December 12 to 16, 1993.

52. The Oral Ganciclovir European and Australian Cooperative Study Group. Intravenous versus oral ganciclovir: European/Australian comparative study of efficacy and safety in the prevention of cytomegalovirus retinitis recurrence in patients with AIDS. AIDS 1995;9:471-7.

53. Spector SA, McKinley G, Drew WL, et al. A randomized, double-blind study of the efficacy and safety of oral ganciclovir for the prevention of cytomegalovirus disease in HIV-infected persons. Second National Conference on Human Retroviruses and Related Infections. Washington, January 29 to February 2, 1995.

54. Drew WL, Miner RC, Crager M, et al. Prevalence of ganciclovir-resistant cytomegalovirus during oral prophylaxis. 3rd Conference on Retroviruses and Opportunistic Infections. Washington, January 28 to February 1, 1996.

55. Brosgart CL, Craig C, Hillman D, et al, for the Terry Beirn Community Programs for Clinical Research on AIDS (CPCRA). A randomized, placebo-controlled trial of the safety and efficacy of oral ganciclovir for prophylaxis of CMV retinal and gastrointestinal mucosal disease in HIV-infected individuals with severe immunosuppression. 35th Interscience Conference on Antimicrobial Agents and Chemotherapy. San Francisco, September 17 to $20,1995$.
56. Melchior WR, Bindlish V, Rybak MJ. Intravitreal ganciclovir for cytomegalovirus retinitis in AIDS patients. Ann Pharmacother 1992;26:36-7.

57. Ward-Able C, Phillips P, Tsoukas CM. The use of oral ganciclovir in the treatment of cytomegalovirus retinitis in patients with AIDS. Can Med Assoc J 1996;154:363-8.

58. Nelson MR, Barter G, Hawkins D, et al. Simultaneous treatment of cytomegalovirus retinitis with ganciclovir and foscarnet. Lancet 1991;338:250.

59. Butler KM, De Smet MD, Husson RN, et al. Treatment of aggressive cytomegalovirus retinitis with ganciclovir in combination with foscarnet in a child infected with HIV. J Pediatr 1992;120:483-6.

60. Dieterich DT, Poles MA, Lew EA, et al. Concurrent use of ganciclovir and foscarnet to treat cytomegalovirus infection in AIDS patients. J Infect Dis 1993;167:1184-8.

61. Kuppermann BD, Flores-Aguilar M, Quiceno JI, et al. Combination ganciclovir and foscarnet in the treatment of clinically resistant cytomegalovirus retinitis in patients with acquired immunodeficiency syndrome. Arch Ophthalmol 1993;111:1359-66.

62. Jabs DA, Studies of Ocular Complications of AIDS Research Group. Combination foscarnet and ganciclovir versus monotherapy for the treatment of relapsed cytomegalovirus retinitis in patients with AIDS: the Cytomegalovirus Retinitis Retreatment Trial. 3rd Conference on Retroviruses and Opportunistic Infections. Washington, January 28 to February 1, 1996.

63. Grossberg HS, Bonnem EM, Buhles WC Jr. GM-CSF with ganciclovir for the treatment of CMV retinitis in AIDS. $\mathrm{N}$ Engl J Med 1989;320:1560. (Lett)

64. Hardy D, Spector S, Posky B, Crumpacker C, et al. Combination of ganciclovir and granulocyte-macrophage colony-stimulating factor in the treatment of cytomegalovirus retinitis in AIDS patients. Eur J Clin Microbiol Infect Dis 1994;(Suppl 2):34-40.

65. Jacobson MA, Stanley HD, Heard SE. Ganciclovir with recombinant methionyl human granulocyte colony-stimulating factor for treatment of cytomegalovirus disease in AIDS patients. AIDS 1992;6:515-6. 


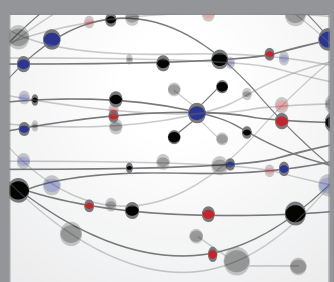

The Scientific World Journal
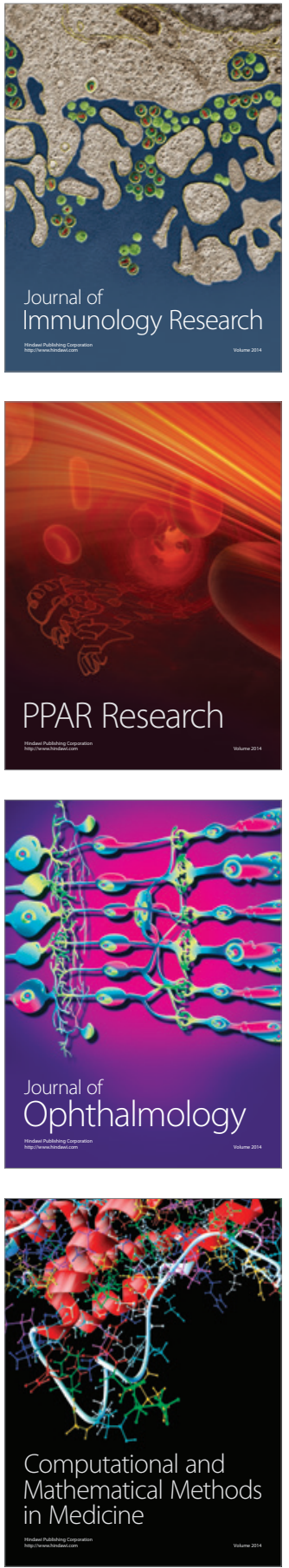

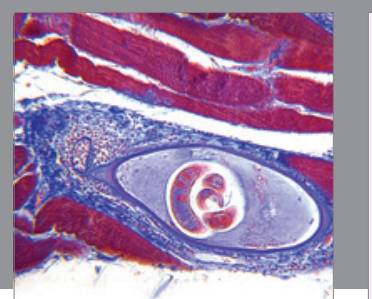

Gastroenterology Research and Practice

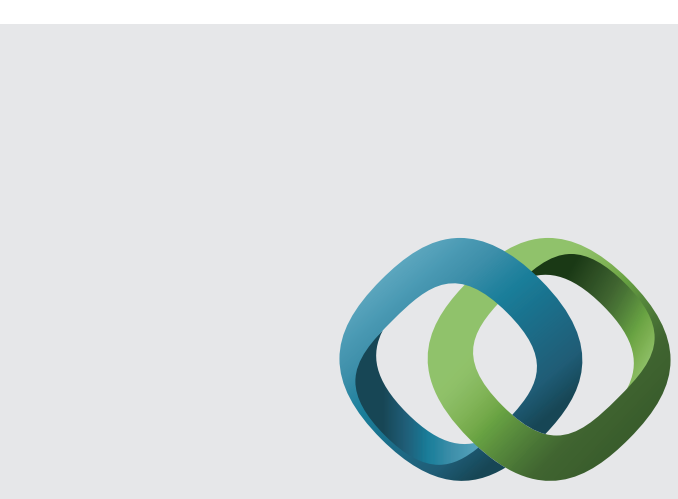

\section{Hindawi}

Submit your manuscripts at

http://www.hindawi.com
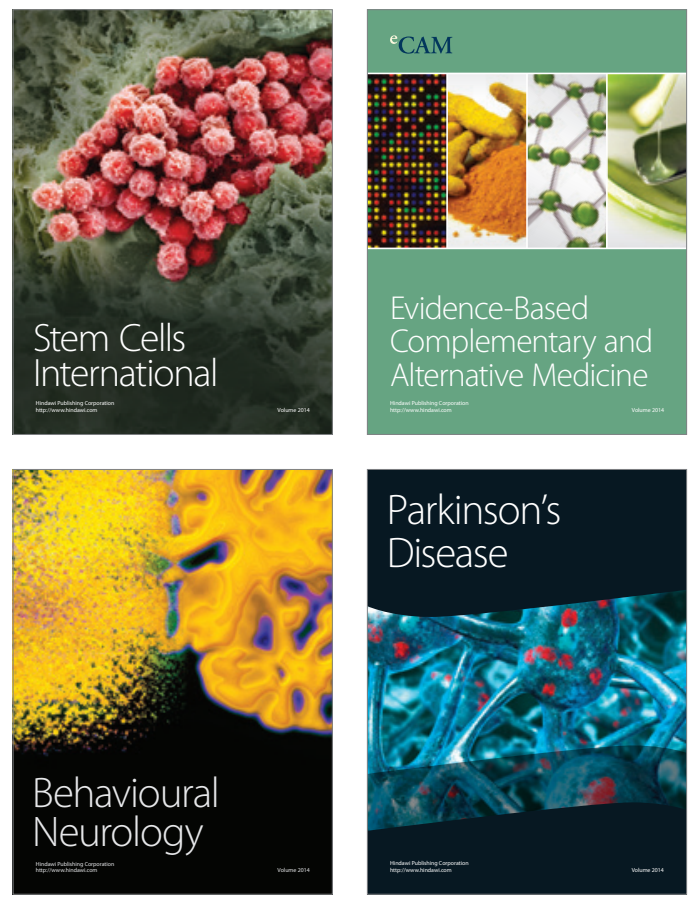
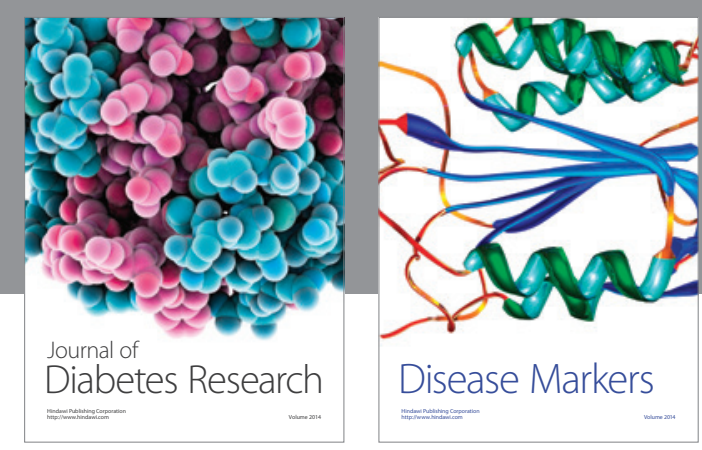

Disease Markers
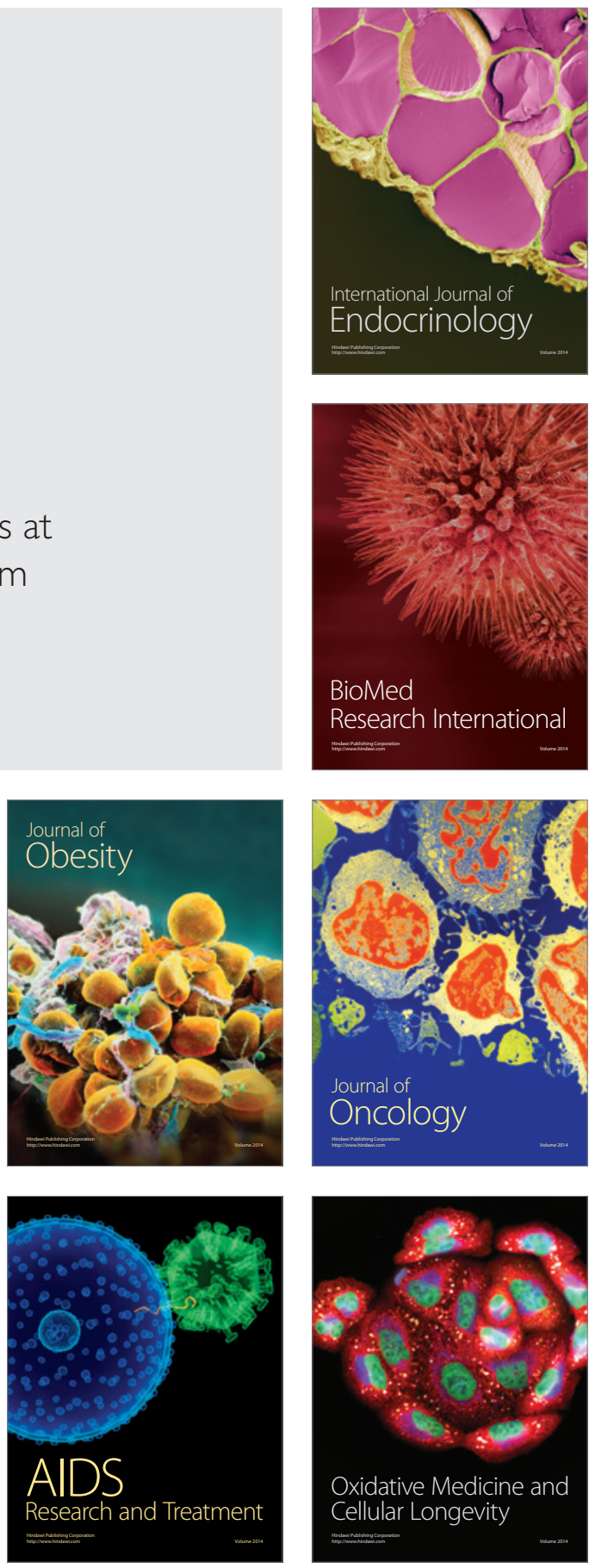